\title{
Comparison of mono- and combination antibiotic therapy for the treatment of Pseudomonas aeruginosa bacteraemia: A cumulative meta-analysis of cohort studies
}

\author{
SU YU TANG ${ }^{1 *}$, SHUN WEN ZHANG ${ }^{2 *}$, JIANG DONG WU ${ }^{3}$, FANG WU $^{3}$, JIE ZHANG $^{1}$, JIANG TAO DONG $^{1}$, \\ PENG GUO ${ }^{1}$, DA LONG ZHANG ${ }^{1}$, JUN TING YANG ${ }^{3}$ and WAN JIANG ZHANG ${ }^{3}$ \\ ${ }^{1}$ Intensive Care Unit, The First Affiliated Hospital, Shihezi University School of Medicine, \\ Shihezi, Xinjiang 832002; ${ }^{2}$ Department of First Clinical Medicine, The First School of Clinical Medicine, \\ Nanjing Medical University, Nanjing, Jiangsu 211166; ${ }^{3}$ Department of Pathophysiology, The First Affiliated Hospital, \\ Shihezi University School of Medicine, Shihezi, Xinjiang 832002, P.R. China
}

Received April 13, 2017; Accepted August 4, 2017

DOI: $10.3892 /$ etm.2018.5727

\begin{abstract}
It is currently unknown whether antibiotic monotherapy or combination therapy is a more effective treatment for patients with Pseudomonas aeruginosa bacteraemia. The present study consists of a systematic review and meta-analysis of cohort studies in associated studies. The treatment options of monotherapy and combination therapy have been compared, to determine which is more effective against $P$. aeruginosa bacteraemia. Several electronic bibliographic databases were systematically searched and clinical studies that compared combination therapy with monotherapy for $P$. aeruginosa bacteraemia were identified. Dersimonian and Laird's random-effects models were used to generate summary estimates of the effects and to assess their association according to different patient characteristics and research quality standards. A total of 17 studies were selected, 3 of which were prospective while the remaining 14 were retrospective. The studies involved a total of 2,504 patients. Significant differences between combination therapy and monotherapy treatment were not found when the data were combined (odds ratio $(\mathrm{OR})=0.81,95 \%$ confidence interval $(\mathrm{CI})=0.61-1.08 ; \mathrm{P}=0.035)$. The results demonstrated strength in a number of stratification and sensitivity analyses. The variables used included study type, treatment quality score and survival rate of subgroup analysis. To conduct cumulative meta-analysis, the number of
\end{abstract}

Correspondence to: Dr Wan Jiang Zhang, Department of Pathophysiology, The First Affiliated Hospital, Shihezi University School of Medicine, 107 North Second Road, Shihezi, Xinjiang 832002, P.R. China

E-mail: zwj1117@126.com

*Contributed equally

Key words: antibiotic cumulative meta-analysis, monotherapy, combination therapy, mortality, Pseudomonas aeruginosa bacteraemia years and samples were calculated. The OR value and 95\% CI were stable and demonstrated good change trend. According to the size of the sample order following accumulation, OR values and $95 \%$ CI $(0.89,0.76-1.04)$ exhibited a narrow range. Neither combination therapy or monotherapy exhibited significant effects on the mortality of patients with $P$. aeruginosa bacteraemia. Future research is required and should include large, well-designed prospective cohorts, and grouped clinical studies.

\section{Introduction}

Pseudomonas aeruginosa is a common clinical cause of gram-negative bacterial, nosocomial infections (1), and causes serious infections in neutropenic and immunocompromised patients (2). Within intensive care units, $P$. aeruginosa has become the most common gram-negative bacterial species associated with severe hospital-acquired infections $(2,3)$. At present, the worldwide morbidity and mortality rates of P. aeruginosa are 18 and $61 \%$ respectively (1-3). The treatment of $P$. aeruginosa infections in a clinical setting remains a notable challenge. The capacity of patients to ingest the appropriate antibiotics in a timely manner positively affects prognosis of severe pseudomonas-infection (4). As such, this variable serves as an important controllable risk factor $(4,5)$. Clinical infection with $P$. aeruginosa may be associated with an increase in 30-day mortality in patients. Treatment with appropriate antibiotics, such as $\beta$-lactam and fluoroquinolone, is associated with the prognosis (6). However, the use of appropriate antibiotic treatment does not consistently show satisfactory effects on patients $(7,8)$. It has previously been suggested that the inappropriate use of antibiotics in the treatment of $P$. aeruginosa bacteraemia may be minimised by a combination antibiotic regimen, in which the sensitivity of results is determined following treatment (8). Inappropriate use of empirical antibiotic therapy has been identified as an independent contributor to the high hospital mortality rate of $P$. aeruginosa bacteraemia $(8,9)$. Combination therapy has been shown to yield improved results compared with 
single treatment of $P$. aeruginosa bacteraemia $(6,9)$, and combination empirical antimicrobial therapy directed against gram-negative bacteria may be a more appropriate treatment approach than monotherapy (10). Despite the merits of relevant studies on empirical combination therapy, it is still unclear whether the use of combination therapy is more effective than monotherapy in treating $P$. aeruginosa infection (10-18). In the present study a meta-analysis was conducted and the mortality of patients treated with either combination therapy or the appropriate monotherapy for $P$. aeruginosa bacteraemia was compared and evaluated.

\section{Materials and methods}

Search terms. Several electronic bibliographic databases were searched including the Chinese Biomedical Literature Database (Wanfang, China), China Academic Journals Full-text database, Cochrane Library, PubMed and Embase for the identification of relevant studies (as of April 2017). The included search terms were: Pseudomonas aeruginosa, bacteremia, monotherapy, combination therapy, antibiotic, mortality and outcome. The databases were searched manually to identify potentially relevant studies. The reference lists of all retrieved articles were also searched to find research that could qualify for the study. Only articles written in Chinese or English were considered; articles written in German, French, Spanish, Italian and Greek were not evaluated. Ultimately, all included papers were written in English. The study inclusion criteria were as follows: i) The study compared the efficacy of monotherapy and combination therapy; ii) retrospective and prospective studies; iii) the treatments discussed in the study included at least one antibiotic agent, which was reported following sustained or initial antibacterial spectrum results (8); and iv) the study results included data on mortality.

Study selection. Two experienced independent reviewers (S-YT and S-WZ) subsequently read through the results and decided which studies were appropriate to be included in the meta-analysis (5,10-25). Any differences in opinion between the two reviewers were resolved by discussion until a consensus was reached. The following data was extracted from each qualified study: Name of first author, type of publication, type of study design, gender and age of patients, sample size, length of hospital stay, type of treatment, type and choice of drugs, mortality, outcomes, number of different populations, and odds ratio (OR) and 95\% confidence interval (CI) results. The possible risk estimates were extracted and adjusted using hybrid variables.

Quality assessment. The selected studies were evaluated using a system based on the cohort study using the Newcastle-Ottawa scale (26), which provides a score for studies between 1-9 'stars'. Three aspects were used to assess the quality of studies: i) Choice of learning study, ii) organisational evaluation and iii) evaluation of comparison results. As there is dispute over the number of stars that must be used as an indicator of high-quality studies (27-33), the included studies were compared; studies that received $\geq 7$ stars $(7,8,9)$ were defined as high-quality studies, and those that scored $\leq 6$ were not.
Statistical methods. Statistical analysis was conducted using Stata version 12.0 software (StataCorp LP, College Station, TX, USA). ORs with $95 \%$ CIs were extracted from studies to evaluate the outcomes of mortality. Cochrane's X2 Q and $\mathrm{I}^{2}$ tests were employed to assess the differences in data from different studies. Stochastic models were applied to heterogeneity studies $\left(\mathrm{P}<0.1\right.$ or $\left.\mathrm{I}^{2}>50 \%\right)(34,35)$. The Mantel-Haenszel fixed-effect model was used to calculate pools or studies when $\mathrm{P}>0.10$ and $\mathrm{I}^{2} \leq 50 \%$; otherwise, the Dersimonian and Laird's random-effects model was used to combine results (36). A sensitivity analysis was also conducted to examine the effects of each study on mixed outcomes. To establish the effects of clinical heterogeneity on meta-analysis, a subgroup analysis was conducted based on study characteristics. Egger's precision-weighted linear regression tests and funnel charts were used to assess potential publication bias (37). When a study demonstrated potential publication bias, the nonparametric correction and filling method was applied. The filling method evaluates the possibility of 'missing' studies that may exist and recalculates the pool or merges them $(34,35)$. The results of the meta-analysis were stratified by types of study and treatment. $\mathrm{P}<0.05$ was considered to indicate a statistically significant difference, unless otherwise stated.

\section{Results}

Search results. Fig. 1 demonstrates the process of study selection and the number of studies excluded at each stage. In the initial search 115 studies were identified, and following a review of the titles, 31 studies were considered for inclusion. The summaries of those 31 studies were reviewed and all studies that were considered eligible were retrieved. Among these studies 14 were excluded for the following reasons: 3 studies did not compare monotherapy and combination therapy; 4 studies did not include mortality rate in the assessment of results; 2 were excluded because patient infection did not cause bacteraemia; and 5 were excluded as data could not be extracted. Therefore, following the screening process 17 studies qualified $(5,10-25)$ and were included in the meta-analysis; they covered a total of 2,504 patients with cases of $P$. aeruginosa bacteraemia.

Study characteristics. Within the qualified studies, 14 were retrospective studies and 3 were prospective studies (Fig. 2). There were 5 studies that reported outcomes of empirical treatment and 12 studies that reported outcomes of definitive treatment (Fig. 3). There were 4 studies conducted in the United States, 7 in Europe, 6 in Asia and 1 was conducted in the United States and Singapore (Table I). According to the Newcastle-Ottawa Scale, 16 of the included studies scored $>6$ and were rated as good or excellent quality (Table I).

Mortality. There were 8 studies that used survival for 30 days, 1 that used survival for 14 days and 1 that used survival for 10 days as the desired outcome of the study. There were 7 studies that considered overall survival as the desired outcome. In terms of mortality, significant difference was observed between patients who received definitive treatment compared with those who received the appropriate empirical treatment $(\mathrm{OR}=0.81,95 \% \mathrm{CI}=0.61-1.08$; Fig. 3$)$. 


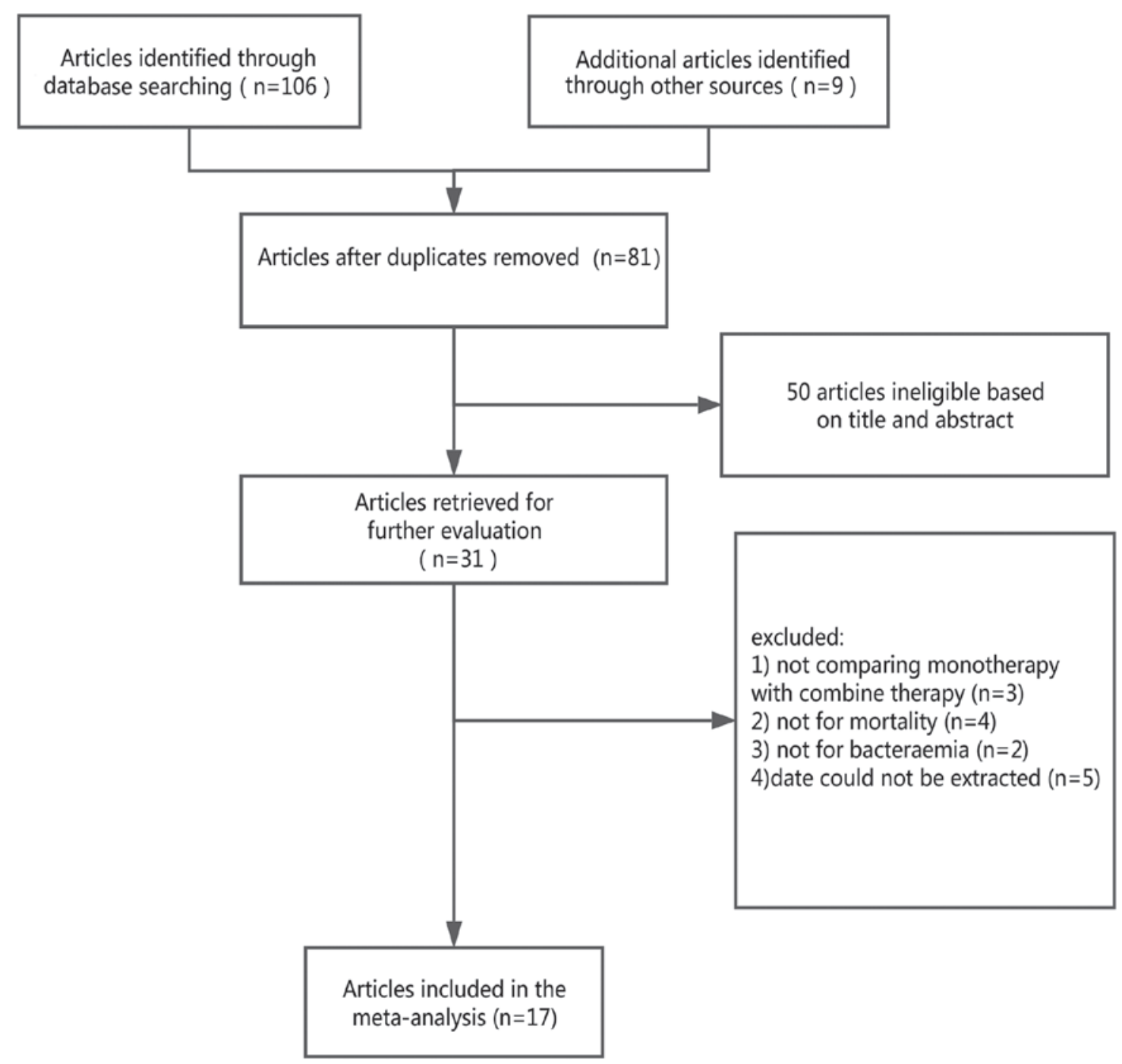

Figure 1. Flow chart of literature study and selection process.

Publication bias. Considering the observed heterogeneity $\left(\mathrm{P}=0.035 ; \mathrm{I}^{2}=42.1 \%\right)$ of the 17 included studies, a random-effects model was used for their analysis (Fig. 2). The following factors were considered: Source of patients, types of study design $(\mathrm{OR}=0.85,95 \% \mathrm{CI}=0.60-1.19, \mathrm{P}=0.034)$, types of treatment $(\mathrm{OR}=0.72,95 \% \mathrm{CI}=0.42-1.23, \mathrm{P}=0.019)$, study population $(\mathrm{OR}=0.74,95 \% \mathrm{CI}=0.41-1.33, \mathrm{P}=0.036)$, literature quality score $(\mathrm{OR}=0.67,95 \% \mathrm{CI}=0.45-1.00$, $\mathrm{P}=0.082)$, and mortality of subgroup stratification analysis $(\mathrm{OR}=1.17,95 \% \mathrm{CI}=0.75-1.85, \mathrm{P}=0.117$; Table II). Retrospective and prospective studies were significantly different in subgroup analysis. Visual inspection of the funnel plots revealed asymmetry among studies (Fig. 4). Consolidation effect was assessed to review the influence results for each study (Fig. 5). Begger's and Egger's tests were conducted to determine publication bias (Figs. 6 and 7) and L'Abbé analysis was performed to assess the heterogeneity of effect sizes, which revealed no marked heterogeneity (Fig. 8). The Z-value and P-value of Begger's test reached 0.21 and 0.805 , respectively, and the t-value and P-value of Egger's test totalled -0.24 and 0.815 respectively. Both P-values of Egger's test and Begger's test were $>0.05$. Therefore, these results indicated that there was no compelling evidence to affirm that results obtained were free from published publication bias.

Subgroup and sensitivity analysis. Table II demonstrates the stratified analysis designed to focus OR of 0.85 (95\% CI=0.60-1.19) for 14 retrospective cohorts and the 12 studies with specific definitive therapy OR of 0.88 (95\% CI=0.62-1.24). A strong correlation was identified in studies conducted in Asian countries, and study quality and mortality did not significantly affect the results (Figs. 9-11).

The contribution of studies to overall prevalence and 95\% CIs was evaluated. In sensitivity analyses, surveyed time strip was omitted and then results were combined with a single dataset on pooled ORs. Corresponding pooled ORs did not change significantly from $0.67(95 \% \mathrm{CI}=0.45-1.00)$ to 0.85 (95\% CI=0.60-1.19). Therefore, the results obtained were considered statistically strong.

Cumulative meta-analysis. Heterogeneity inspection was conducted initially and the effects, combined effects and their corresponding CI were evaluated to obtain the Q statistic and its corresponding P-value. Heterogeneity=27.63 (degree of freedom $=16$ ), $\mathrm{P}=0.035$ and $\mathrm{I}^{2}=42.1 \%$. Given 


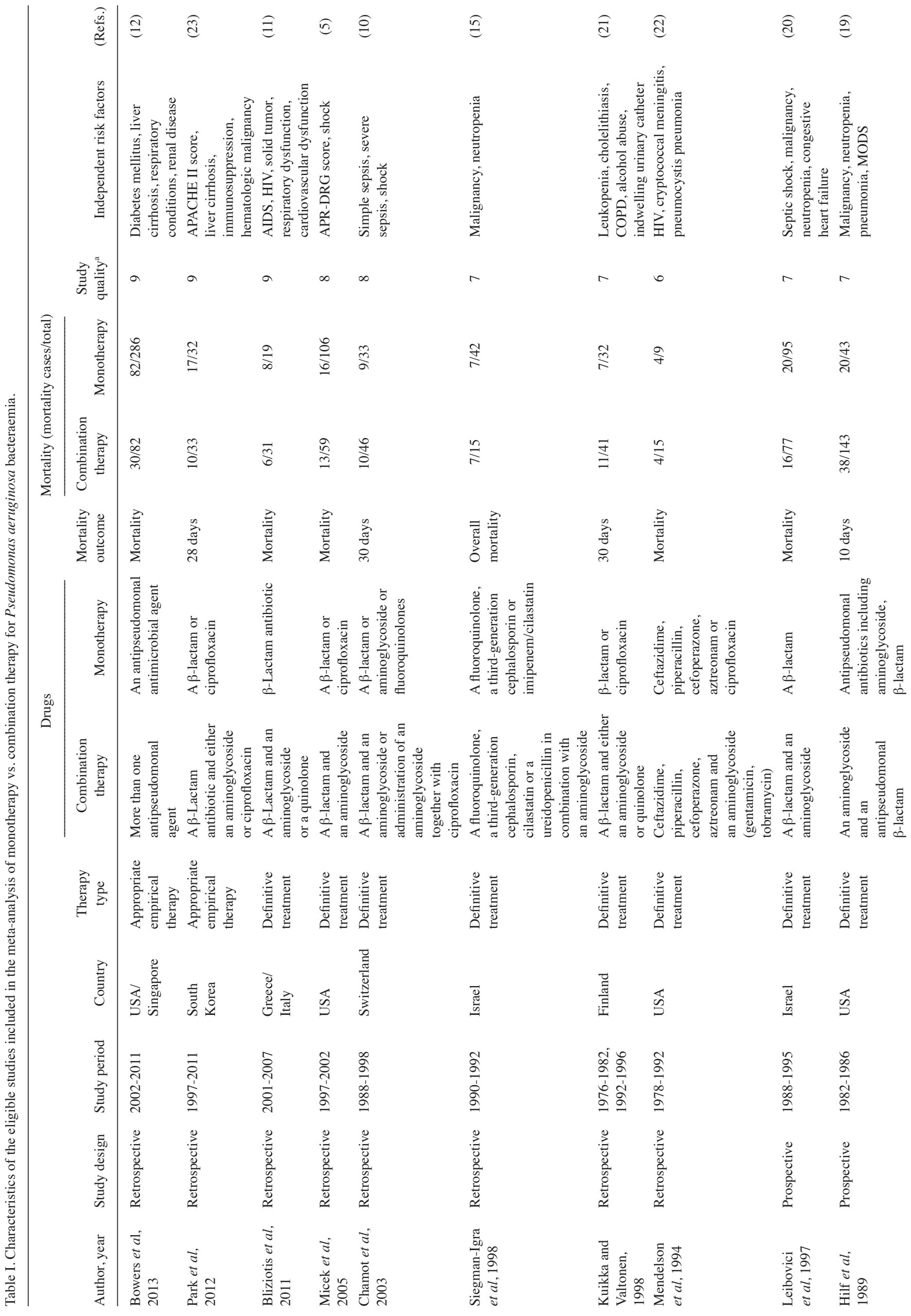




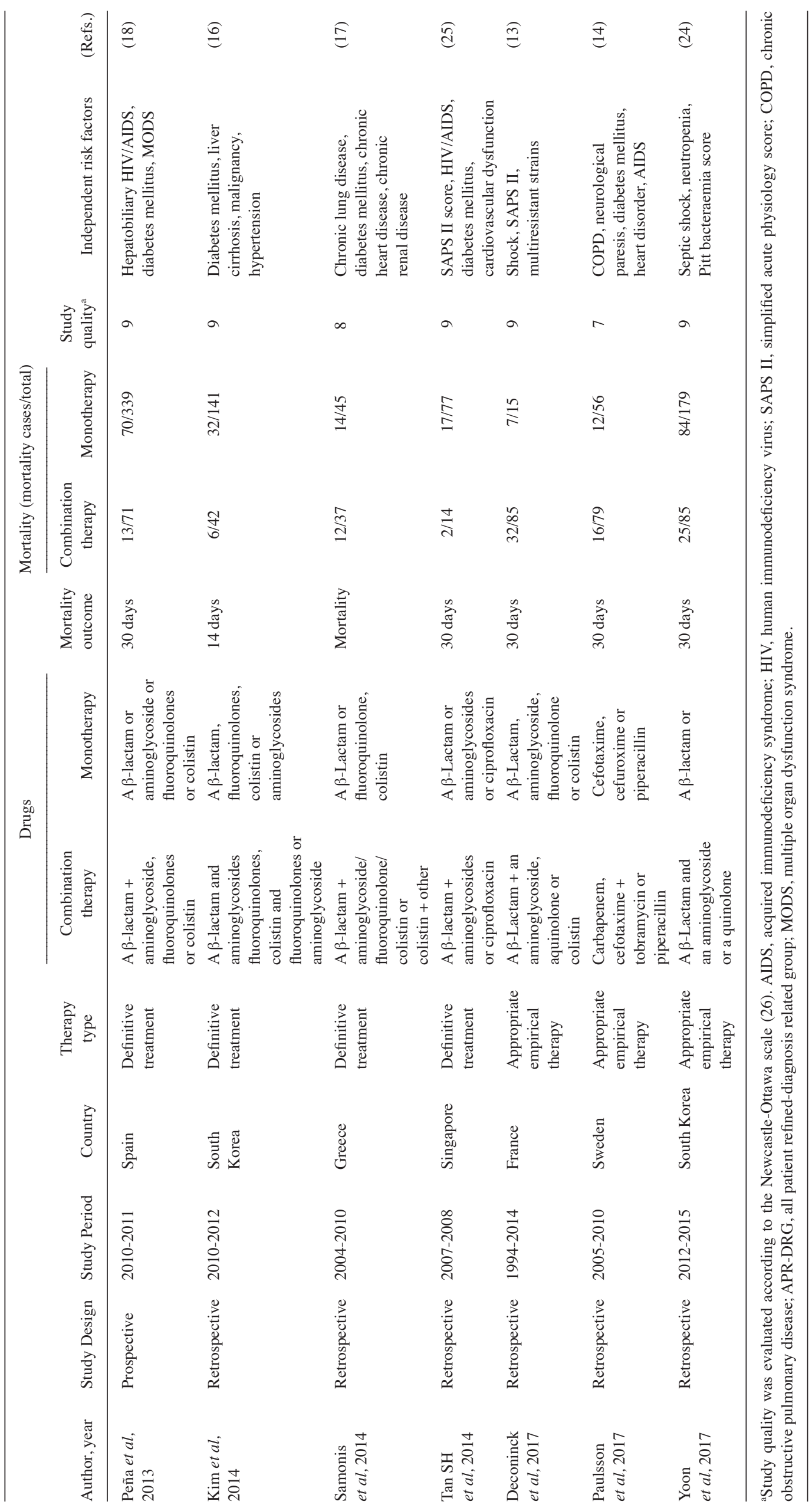


Table II. Stratified analyses of pooled ORs.

\begin{tabular}{|c|c|c|c|c|c|c|}
\hline \multirow[b]{2}{*}{ Factor } & \multirow[b]{2}{*}{ Level } & \multirow{2}{*}{$\begin{array}{l}\text { No. of } \\
\text { studies }\end{array}$} & \multirow{2}{*}{$\begin{array}{r}\text { Pooled OR } \\
(95 \% \mathrm{CI})^{\mathrm{a}}\end{array}$} & \multicolumn{2}{|c|}{ Heterogeneity test } & \multirow[b]{2}{*}{ (Refs.) } \\
\hline & & & & P-value & $\mathrm{I}^{2}(\%)$ & \\
\hline All studies & - & 17 & $0.81(0.61-1.08)$ & 0.035 & 42.1 & $(5,10-18,31-37)$ \\
\hline \multirow[t]{2}{*}{ Study population } & Asian & 6 & $0.74(0.41,1.33)$ & 0.036 & 58.0 & $(15,16,32,35-37)$ \\
\hline & Non-Asian ${ }^{\mathrm{a}}$ & 11 & $0.88(0.65,1.20)$ & 0.196 & 26.0 & $(5,10-14,17,18,31,33,34)$ \\
\hline \multirow[t]{2}{*}{ Study design } & Prospective cohort ${ }^{\mathrm{a}}$ & 3 & $0.71(0.42,1.18)$ & 0.193 & 39.2 & $(18,31,32)$ \\
\hline & Retrospective cohort & 14 & $0.85(0.60,1.19)$ & 0.034 & 45.1 & $(5,10-17,33-37)$ \\
\hline \multirow[t]{2}{*}{ Therapy type } & Definitive therapy & 12 & $0.88(0.62,1.24)$ & 0.173 & 27.7 & $(5,10,11,15-18,32-35,37)$ \\
\hline & Appropriate empirical therapy & 5 & $0.72(0.42,1.23)$ & 0.019 & 65.9 & $(12-14,31,36)$ \\
\hline \multirow[t]{4}{*}{ Study quality } & 9 stars & 8 & $0.67(0.45,1.00)$ & 0.082 & 44.5 & $(11-13,16,18,35-37)$ \\
\hline & 8 stars & 3 & $1.15(0.68,1.95)$ & 0.515 & - & $(5,10,17)$ \\
\hline & 7 stars & 5 & $1.03(0.53,1.99)$ & 0.029 & 63.0 & $(14,15,31-33)$ \\
\hline & 6 stars $^{\mathrm{b}}$ & 1 & $0.45(0.08,2.60)$ & - & - & $(34)$ \\
\hline \multirow[t]{4}{*}{ Outcome } & Overall mortality & 7 & $1.17(0.75,1.85)$ & 0.117 & 41.1 & $(5,11,12,14,15,17,34)$ \\
\hline & 30-day mortality & 8 & $0.67(0.49,0.90)$ & 0.611 & 0 & $(10,13,14,18,33,35-37)$ \\
\hline & 14-day mortality ${ }^{b}$ & 1 & $0.57(0.22,1.47)$ & - & - & $(16)$ \\
\hline & 10-day mortality ${ }^{\mathrm{b}}$ & 1 & $0.42(0.21,0.84)$ & - & - & (31) \\
\hline
\end{tabular}

${ }^{a}$ The fixed-effect model was used to calculate the pooled OR if $\mathrm{P}>0.10$ and $\mathrm{I}^{2} \leq 50 \%$; otherwise, the random-effect model was used to merge the results. ${ }^{\mathrm{b}} \mathrm{Pooled}$ ORs were not provided when stratified analysis only included one or two studies. CI, confidence interval; OR, odds ratio.

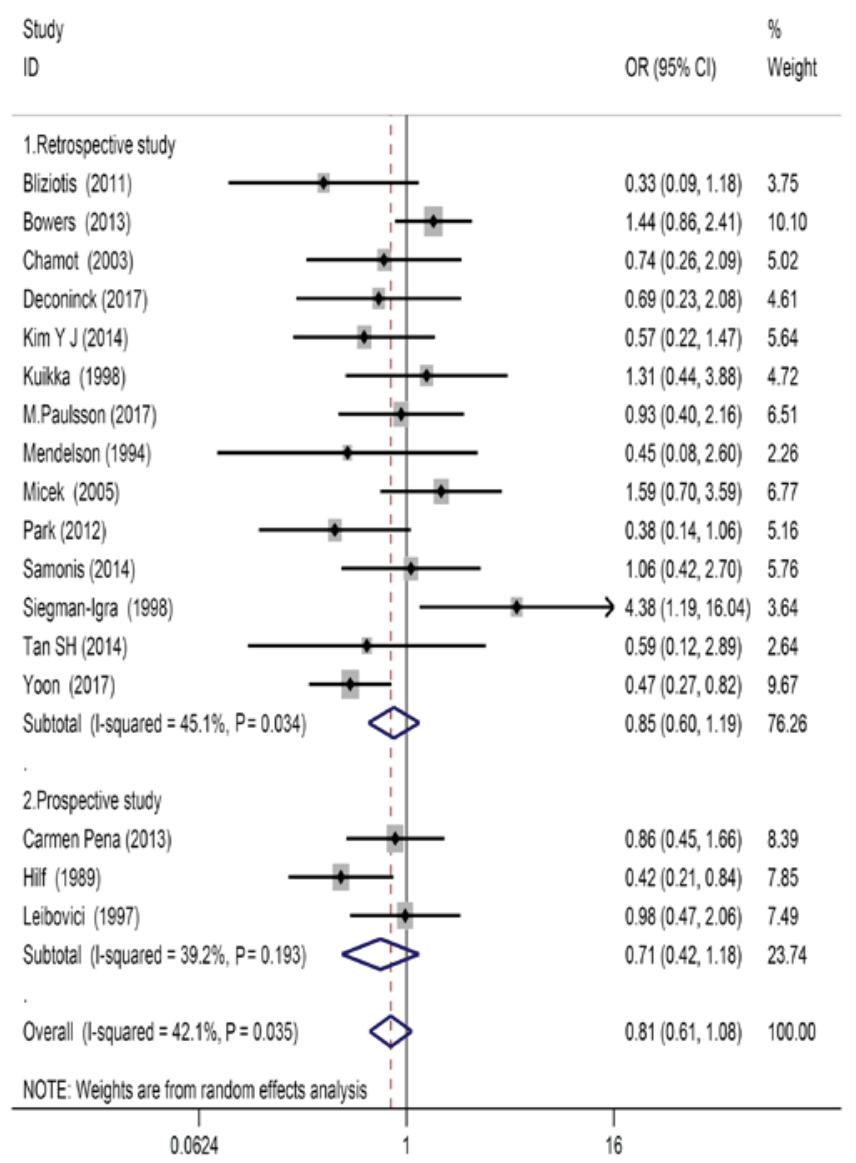

Figure 2. Forest plot of comparison of monotherapy and combination therapy for Pseudomonas aeruginosa bacteraemia by study design. OR, odds ratio; CI, confidence interval.

that no clear heterogeneity was observed among studies, cumulative analysis was performed using a random-effects model. Fixed number of years and sample size were

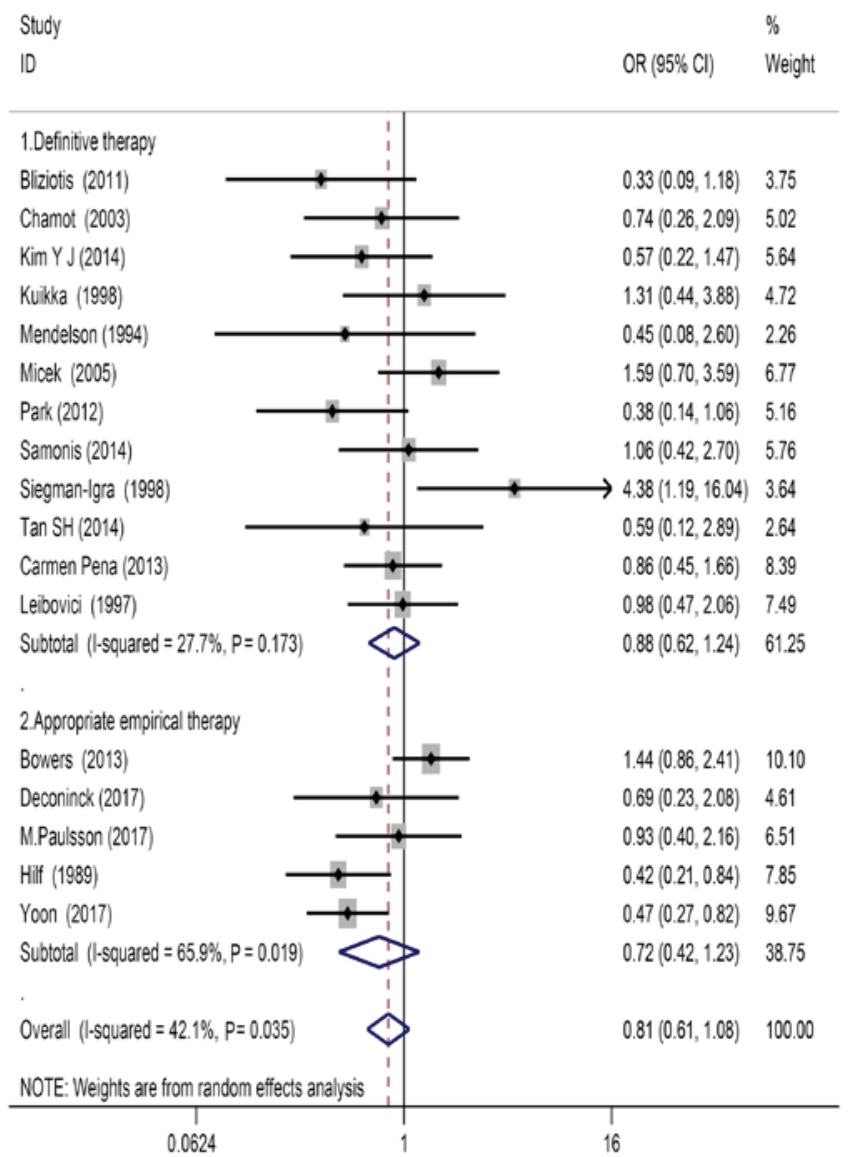

Figure 3. Forest plot of comparison of monotherapy and combination therapy for Pseudomonas aeruginosa bacteraemia by type of treatment. OR, odds ratio; $\mathrm{CI}$, confidence interval.

considered for cumulative meta-analysis. Organised in chronological order, OR value and $95 \%$ CI were stable and demonstrated good change trend, aside from the study by 


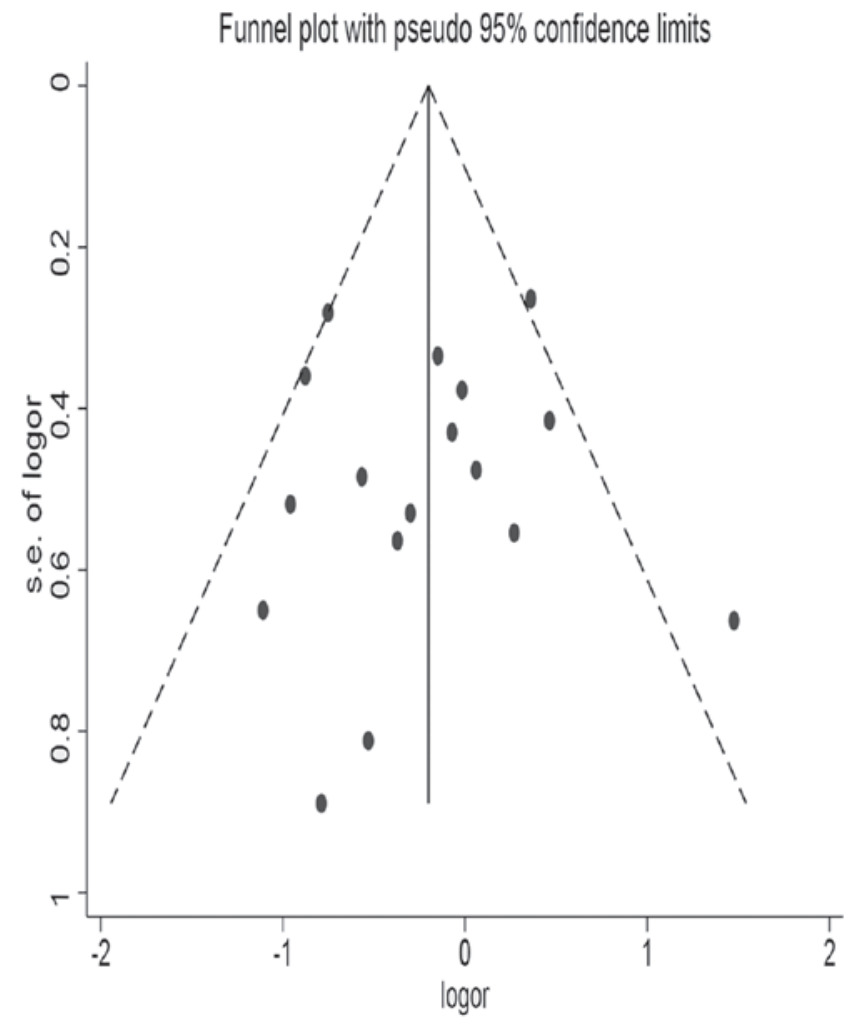

Figure 4. Funnel plot with pseudo 95\% confidence limits. s.e., standard error.

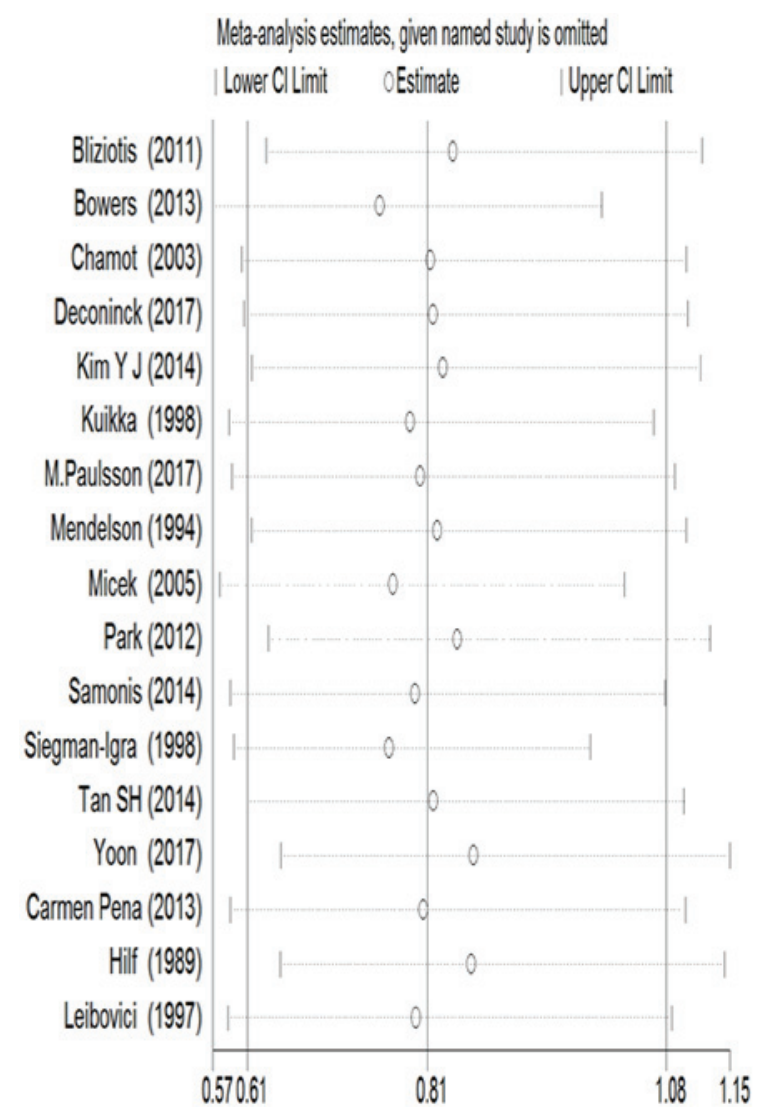

Figure 5. Quantity of studies on combined effects. CI, confidence interval.

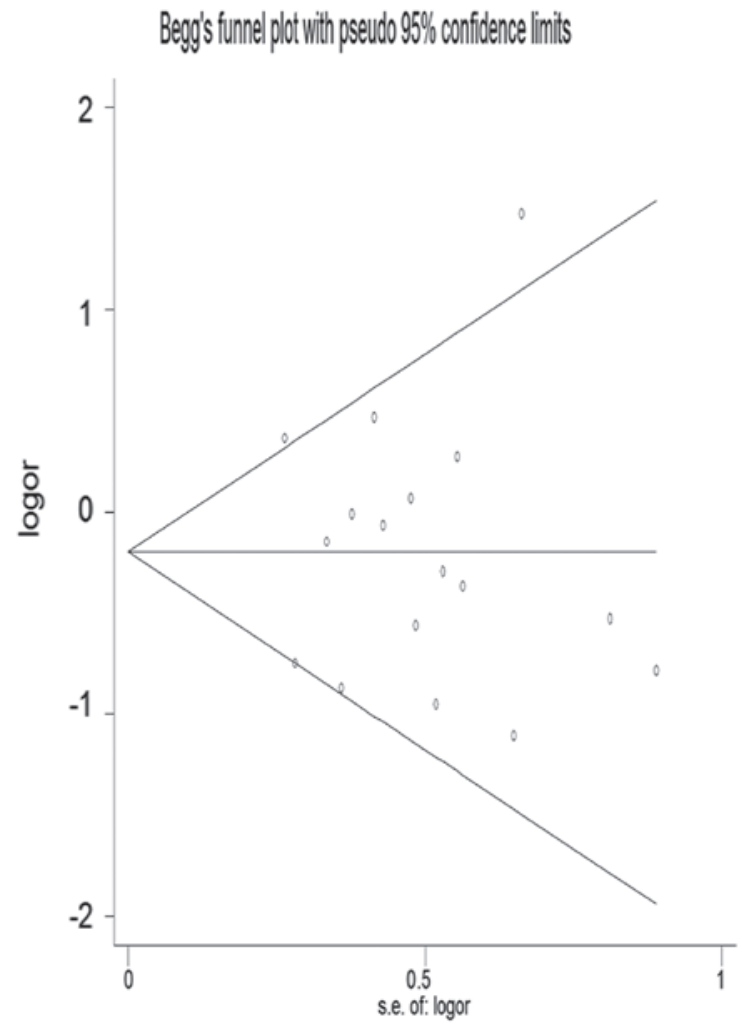

Figure 6. Odds ratio of publication bias plots. s.e., standard error.

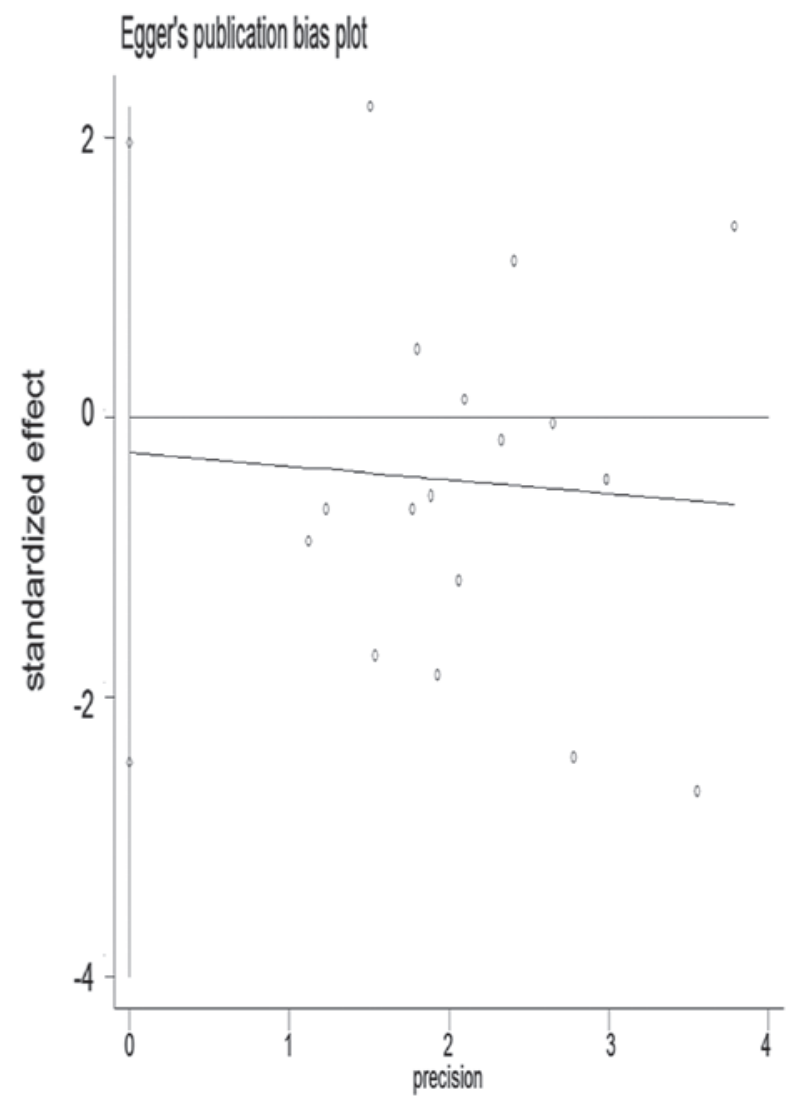

Figure 7. Egger's publication bias plots
Bliziotis et al (11) (Fig. 12). Based on sample size order following accumulation, when a large sample was included, the range of OR values and $95 \%$ CI $(0.89 ; 0.76-1.04)$ was decreased (Fig. 13). 


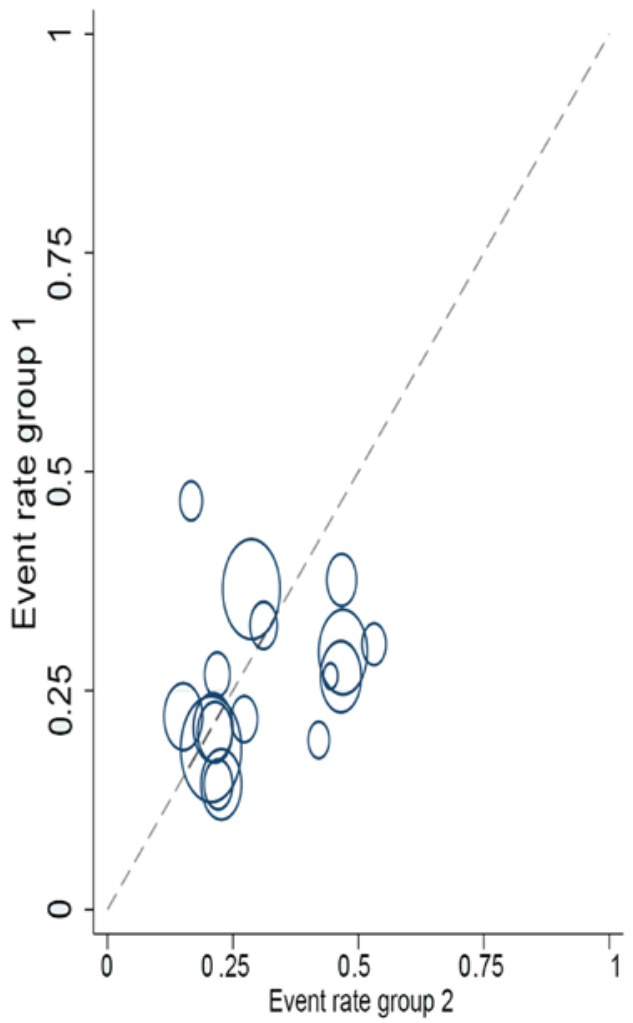

Figure 8. L'Abbé analysis of heterogeneity of effect sizes.

Study

iD$$
9
$$

Bliziotis (2011)

Bowers (2013)

Deconinok (2017)

$\operatorname{Kim} Y \mathrm{~J}(2014)$

Park (2012)

Tan SH (2014)

Yoon (2017)

Carmen Pena (2013)

Subtotal (1-squared $=44.5 \%, P=0.082$ )

8

Chamot (2003)

Micek (2005)

Samonis (2014)

Subtotal (1-squared $=0.0 \%, P=0.515)$

7

Kukka (1998)

M.Paulsson (2017)

Siegman-lgra (1998)

Hili (1989)

Lebonici (1997)

Subtotal (1-squared $=63.0 \%, P=0.029$

6

Mendelison (1994)

Subtotal (1-squared $=. \%, P=$.)

Overall (1-squared $=42.1 \%, P=0.035)$

NOTE: Weights are from rancom effects analysis

0.0624

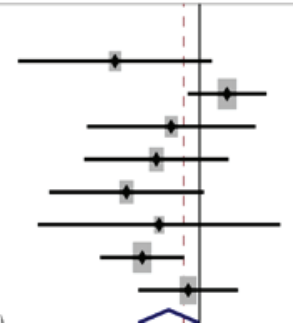

$\mathrm{OR}(05 \% \mathrm{Cl}) \quad$ Weight

$0.33(0.09,1.18) \quad 3.75$

$1.44(0.88,2.41) \quad 10.10$

$0.69(0.23,2.08) \quad 4.61$

$0.57(0.22,1.47) \quad 5.64$

$0.38(0.14,1.06) \quad 5.16$

$0.59(0.12,2.89) \quad 2.64$

$0.47(0.27,0.82) \quad 9.67$

$0.86(0.45,1.66) \quad 8.39$

$0.67(0.45,1.00) \quad 49.96$

$0.74(0.26,2.09) \quad 5.02$ $1.59(0.70,3.59) \quad 6.77$

$1.06(0.42,2.70) \quad 5.76$

$1.15(0.68,1.95) \quad 17.55$

$1.31(0.44,3.88) \quad 4.72$ $0.93(0.40,2.16) \quad 6.51$

$438(1.19,16.04) 3.64$ $0.42(0.21,0.84) \quad 7.85$ $0.98(0.47,2.06) \quad 7.49$ $1.03(0.53,1.99) \quad 30.23$

$0.45(0.08,2.60) \quad 2.26$ $0.45(0.08,2.00) \quad 2.26$ $0.81(0.61,1.08) \quad 100.00$

Figure 9. Forest plot of comparison of monotherapy and combination therapy for $P$. aeruginosa bacteraemia by quality evaluation. $\mathrm{I}^{2}$ and $\mathrm{P}$-values were not provided when stratified analysis only included one or two studies. OR, odds ratio; $\mathrm{CI}$, confidence interval.

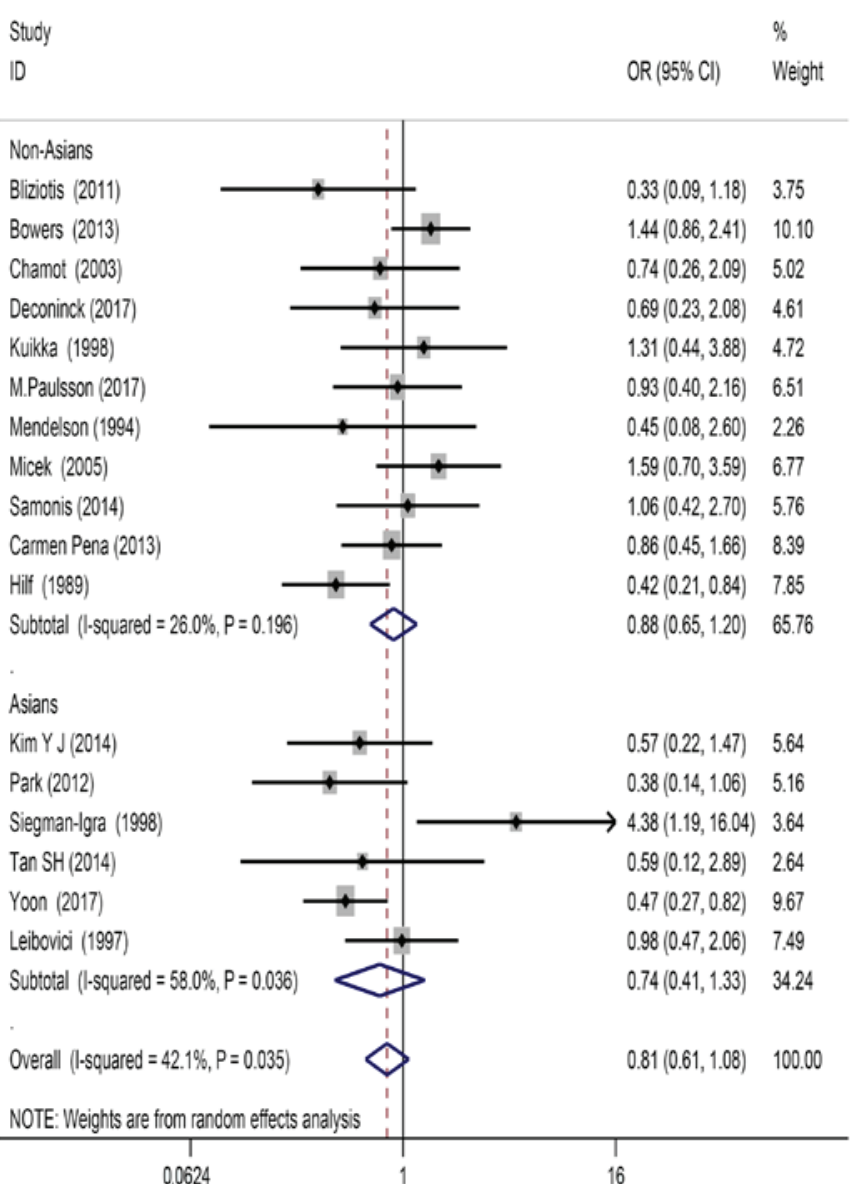

Figure 10. Forest plot of comparison of monotherapy and combination therapy for $P$. aeruginosa bacteraemia by regional distribution. OR, odds ratio; $\mathrm{CI}$, confidence interval.

\section{Discussion}

The present study consisted of a meta-analysis that compared the effects of using either a combination of antibiotics or a single antibiotic for the treatment of $P$. aeruginosa bacteraemia. A total of 17 studies were systematically reviewed and compared. The antibiotic and appropriate empirical treatments used were determined by extracting data from the studies, and the patients' all-cause mortality associated with $P$. aeruginosa bacteraemia was analysed. No significant differences were identified between monotherapy and combination therapy in regards to mortality. Therefore, definite combination therapy and appropriate combination of therapies failed to independently provide additional benefits for patient treatment. However, in the subgroup analysis process significant differences were observed in types of study design and types of treatment. In particular, the use of $\beta$-lactam and cephalosporin antibiotics as an empirical treatment were able to significantly reduce the mortality rate of patients.

In clinical treatment, patient mortality associated with $P$. aeruginosa bacteraemia remains high (61\%) despite the progress of antibiotic therapy; thus, an improved treatment approach is required (38). Bliziotis et al (11) reported that combination therapy was superior to monotherapy in treating patients with $P$. aeruginosa bacteraemia; however, $81 \%$ of patients $(25 / 31)$ who received monotherapy only received 


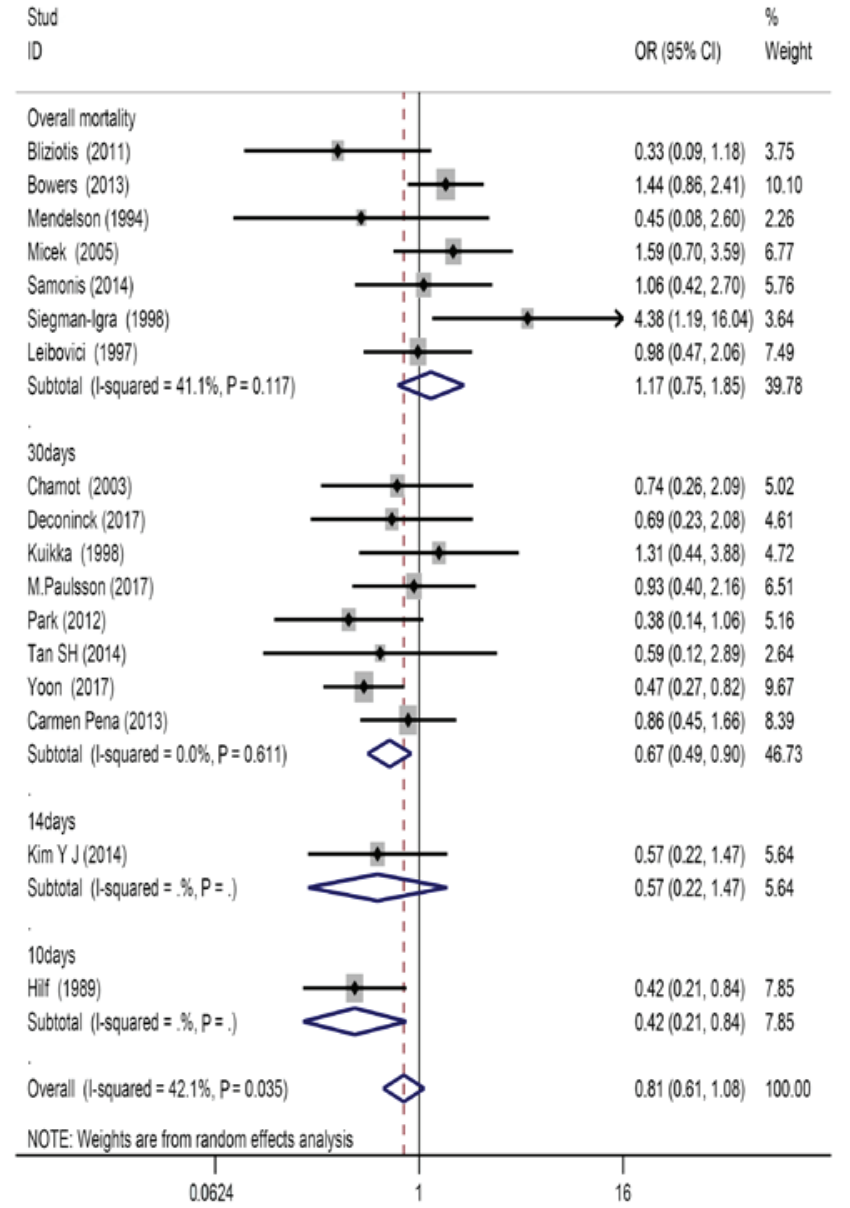

Figure 11. Forest plot of comparison of monotherapy and combination therapy for $P$. aeruginosa bacteraemia by mortality. $\mathrm{I}^{2}$ and $\mathrm{P}$-values were not provided when stratified analysis only included one or two studies. OR, odds ratio; $\mathrm{CI}$, confidence interval.

$\beta$-lactam, which cannot be considered the optimum monotherapy owing to the increased mortality rate associated with this drug compared with other monotherapies $(20,21,39)$. Micek et al (5) observed that compared with single antibiotics, combination therapy yielded improved effects. However, given the open clinical design of the study, patients in a single-treatment group may be more likely to receive additional antibiotics and were therefore considered treatment failures in these studies. The number of patients included in meta-analysed subgroups were assessed in each randomised controlled study. As such, the baseline comparable $P$. aeruginosa bacteraemia infection between monotherapy and combination therapy groups was not established. Confounding factors in the remaining studies may be attributed to lack of randomisation, thus leading to incorrect conclusions (39). Another previous meta-analysis also performed a similar comparison by using $\beta$-lactam monotherapy and a combination of $\beta$-lactam and aminoglycosides on immunoreactive sepsis patients (6); the results revealed that association of combination therapy with single treatments was not advantageous in all-cause mortality or other treatment failure in patient subgroups with $P$. aeruginosa bacteraemia infection. By contrast, another study focused on analysis of patients with gram-negative bacteraemia. Following subgroup analysis of the results it was identified that combination antibiotic treatment led to a

\begin{tabular}{|c|c|c|c|}
\hline author & year & & $\operatorname{RR}(95 \% \mathrm{Cl})$ \\
\hline Hilf & 1989 & $\rightarrow$ & $0.86(0.74,0.99)$ \\
\hline Mendelson & 1994 & $\rightarrow$ & $0.94(0.76,1.18)$ \\
\hline Leibovici & 1997 & + & $0.86(0.75,0.99)$ \\
\hline Kulkka & 1998 & $\rightarrow$ & $0.96(0.76,1.23)$ \\
\hline Siegman-Igra & 1998 & - & $0.99(0.83,1.19)$ \\
\hline Chamot & 2003 & - & $1.05(0.78,1.40)$ \\
\hline Micek & 2005 & - & $0.99(0.80,1.22)$ \\
\hline Bliziotis & $2011 \leftarrow$ & 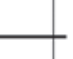 & $0.46(0.19,1.12)$ \\
\hline Park & 2012 & $\rightarrow$ & $0.94(0.77,1.15)$ \\
\hline Bowers & 2013 & - & $1.10(0.81,1.50)$ \\
\hline Carmen Pena & 2013 & + & $0.89(0.76,1.04)$ \\
\hline $\operatorname{Kim} Y \mathrm{~J}$ & 2014 & $\rightarrow$ & $0.94(0.73,1.21)$ \\
\hline Samonis & 2014 & $\rightarrow$ & $0.95(0.79,1.15)$ \\
\hline Tan SH & 2014 & - & $0.98(0.82,1.18)$ \\
\hline Deconinck & 2017 & 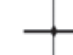 & $1.00(0.77,1.31)$ \\
\hline M.Paulsson & 2017 & $\rightarrow$ & $0.96(0.77,1.21)$ \\
\hline Yoon & 2017 & $\rightarrow$ & $0.89(0.76,1.05)$ \\
\hline & 0.189 & 1 & 5.3 \\
\hline
\end{tabular}

Figure 12. Accumulated studies in chronological order. CI, confidence interval; RR, relative risk.

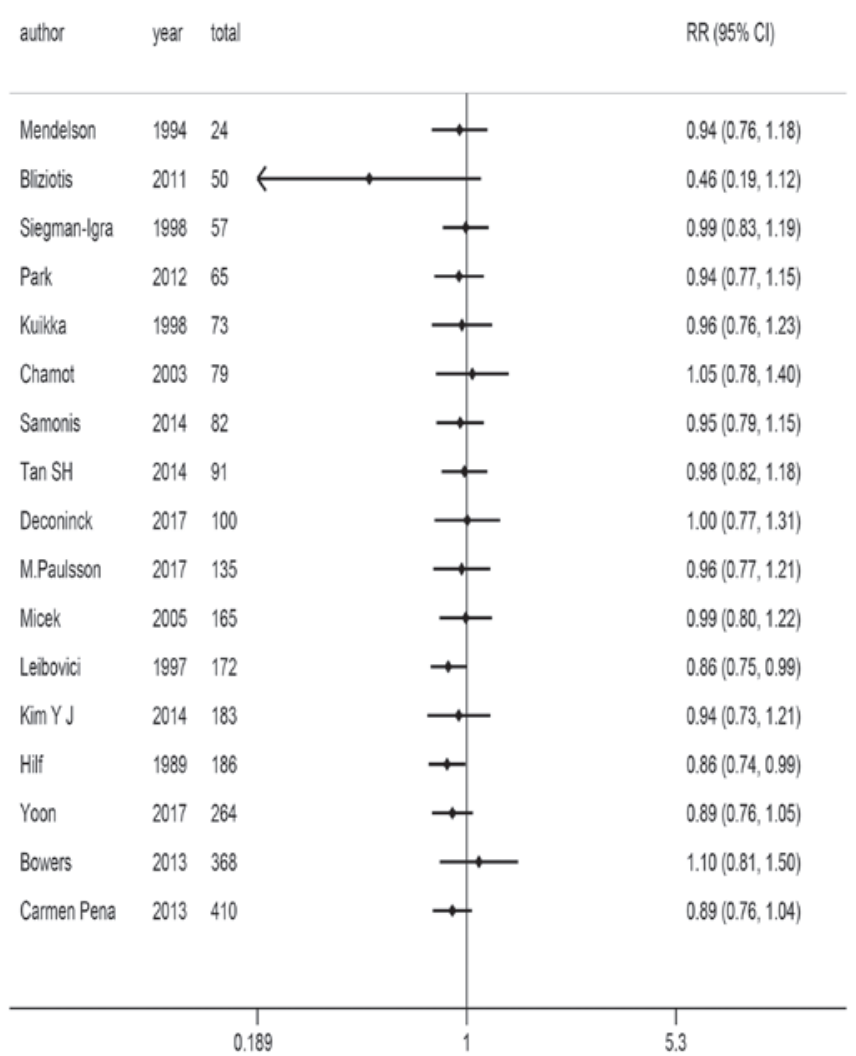

Figure 13. Size of sample order following accumulation. CI, confidence interval; RR, relative risk.

reduction in the mortality rates of $P$. aeruginosa bacteraemia compared with monotherapy, however these results were not 
representative of all gram-negative bacteraemia studied $(6,40)$. As previously revealed, inferior quality and heterogeneity of studies considered in these meta-analyses resulted in unreliable clinical data. Differences among patients were also notable and results often differed (39). A recent meta-analysis studied the effects of carbapenem-resistant $P$. aeruginosa bacteraemia on mortality (41). Another meta-analysis study on the benefits of clinical treatment was conducted through the use of an empirical combination therapy using $\beta$-lactam combined with an aminoglycoside or fluoroquinolones and $\beta$-lactam monotherapy for $P$. aeruginosa infection (42). In a subgroup analysis (5 studies) of $P$. aeruginosa bacteraemia, the results of the clinical treatment demonstrated no significant difference in mortality between patients treated with monotherapy and combination therapy. According to the above variances, a meta-analysis was conducted in the present study; to the best of our knowledge $P$. aeruginosa bacteraemia, although common in patients with bacteraemia, is not very common in clinical settings. Thus, the sample size was limited. The present review also indicated limited clinical reviews and prospective study design. Owing to these limitations, baseline comparison of $P$. aeruginosa bacteraemia infection between monotherapy and combination therapy was not established. Therefore, difficulty arose from completing large randomised prospective clinical trials. Patient complications also differed; multidrug-resistant (MDR) $P$. aeruginosa strains became increasingly common and varied in terms of selection of drug types. Therefore, studies were not analysed according to specific antibiotics, as the present meta-analysis was performed with different antimicrobial therapies. In several studies $(13,14,16,18,24)$, comparisons between selected empirical antibiotic therapy and definitive treatment were retrospectively analysed. Other studies rated the Chronic Health Evaluation score of in-patients $(12,16,23,25)$. Appropriate treatment involves antibiotic isolation therapy for certain in-vitro-sensitive agents, especially for aminoglycoside antibiotic-sensitive patients $(19,35)$. The use of monotherapy for treatment of $P$. aeruginosa bacteraemia was considered inappropriate in previous studies comparing single and combination therapies $(10,15)$. Some meta-analyses conducted from the perspective of treatment and mortality compared effectiveness of combination antibiotics and monotherapy in clinical treatment of $P$. aeruginosa (43). The present meta-analysis did not focus on survival rate and quality evaluation. A limitation of the present study was the lack of scope in comparing study type and treatment selection. For patients with MDR bacterial infection and $P$. aeruginosa, providing combination antibiotic therapy may improve results as this method increases possibility of appropriate treatment (42). In addition to the appropriate choice of empirical treatment, the severity of complications is another risk factor that may also affect mortality rate of patients during bacterial infections including $P$. aeruginosa (42). Combination therapy with $P$. aeruginosa also presents potential risks, particularly drug toxicities, including aminoglycoside antibiotics associated with human renal toxicity (6). Likelihood of repeated infection in clinical patients and the increased cost must also be considered in comparing combination therapy with monotherapy.

Limitations of meta-analysis conducted in the present study were recognised. The quality of included studies may be questioned due to incomplete or inaccurate data collection. The research on adjustment of these confusing factors is limited and therefore cannot be studied for potential co-founder influence, including severity of disease and potential for concurrent conditions. The funnel plot and Egger's test indicated a possibility of publication bias, however trim-and-fill analysis revealed that results did not change. Only sensitivity analysis and evaluation, patient source, study types, treatment options and mortality were analysed. Finally, only studies published in English were included. This may introduce language bias, possibly resulting in incomplete study and thus reducing accuracy of analysis of the treatment results.

In conclusion, the results demonstrated no significant difference in mortality between patients administered with combined antibiotic or monotherapy treatment against $P$. aeruginosa bacteraemia. Combination therapy may be associated with clinical treatment of monotherapy, particularly when used in empirical therapy. These results were mainly obtained from retrospective and secondary studies. Thus, no definite conclusions may be drawn regarding combination of effectiveness and single therapy in patients and groups. Relevant evidence obtained was also limited. Therefore, large-scale and well-designed studies must be developed and conducted on credibility of treatment mechanisms to determine whether a causal association exists.

\section{References}

1. Papagheorghe R: Bloodstream infections in immunocompromised hosts. Roum Arch Microbiol Immunol 71: 87-94, 2012.

2. Samonis G, Vardakas KZ, Maraki S, Tansarli GS, Dimopoulou D, Kofteridis DP, Andrianaki AM and Falagas ME: A prospective study of characteristics and outcomes of bacteremia in patients with solid organ or hematologic malignancies. Support Care Cancer 21: 2521-2526, 2013.

3. Bassetti M, Righi E and Viscoli C: Pseudomonas aeruginosa serious infections: Mono or combination antimicrobial therapy? Curr Med Chem 15: 517-522, 2008.

4. Garnacho-Montero J, Sa-Borges M, Sole-Violan J, Barcenilla F, Escoresca-Ortega A, Ochoa M, Cayuela A and Rello J: Optimal management therapy for Pseudomonas aeruginosa ventilator-associated pneumonia: An observational, multicenter study comparing monotherapy with combination antibiotic therapy. Crit Care Med 35: 1888-1895, 2007.

5. Micek ST, Lloyd AE, Ritchie DJ, Reichley RM, Fraser VJ and Kollef MH: Pseudomonas aeruginosa bloodstream infection: Importance of appropriate initial antimicrobial treatment. Antimicrob Agents Chemother 49: 1306-1311, 2005.

6. Paul M, Benuri-Silbiger I, Soares-Weiser K and Leibovici L: Beta lactam monotherapy versus beta lactam-aminoglycoside combination therapy for sepsis in immunocompetent patients: Systematic review and meta-analysis of randomised trials. BMJ 328: 668, 2004.

7. Morata L, Cobos-Trigueros N, Martínez JA, Soriano A, Almela M, Marco F, Sterzik H, Núñez R, Hernández C and Mensa J: Influence of multidrug resistance and appropriate empirical therapy on the 30-day mortality rate of Pseudomonas aeruginosa bacteremia. Antimicrob Agents Chemother 56: 4833-4837, 2012.

8. Micek ST, Welch EC, Khan J, Pervez M, Doherty JA, Reichley RM and Kollef MH: Empiric combination antibiotic therapy is associated with improved outcome against sepsis due to Gram-negative bacteria: A retrospective analysis. Antimicrob Agents Chemother 54: 1742-1748, 2010.

9. Anderson ET, Young LS and Hewitt WL: Antimicrobial synergism in the therapy of gram-negative rod bacteremia. Chemotherapy 24: 45-54, 1978. 
10. Chamot E, Boffi El Amari E, Rohner P and Van Delden C: Effectiveness of combination antimicrobial therapy for Pseudomonas aeruginosa bacteremia. Antimicrob Agents Chemother 47: 2756-2764, 2003.

11. Bliziotis IA, Petrosillo N, Michalopoulos A, Samonis G and Falagas ME: Impact of definitive therapy with beta-lactam monotherapy or combination with an aminoglycoside or a quinolone for Pseudomonas aeruginosa bacteremia. PLoS One 6 : e26470, 2011

12. Bowers DR, Liew YX, Lye DC, Kwa AL, Hsu LY and Tam VH: Outcomes of appropriate empiric combination versus monotherapy for Pseudomonas aeruginosa bacteremia. Antimicrob Agents Chemother 57: 1270-1274, 2013.

13. Deconinck L, Meybeck A, Patoz P, Van Grunderbeeck N, Boussekey N, Chiche A, Delannoy PY, Georges H and Leroy O: Impact of combination therapy and early de-escalation on outcome of ventilator-associated pneumonia caused by Pseudomonas aeruginosa. Infect Dis (Lond) 49: 396-404, 2017

14. Paulsson M, Granrot A, Ahl J, Tham J, Resman F, Riesbeck K and Månsson F: Antimicrobial combination treatment including ciprofloxacin decreased the mortality rate of Pseudomonas aeruginosa bacteraemia: A retrospective cohort study. Eur J Clin Microbiol Infect Dis 36: 1187-1196, 2017.

15. Siegman-Igra $\mathrm{Y}$, Ravona R, Primerman $\mathrm{H}$ and Giladi $\mathrm{M}$ : Pseudomonas aeruginosa bacteremia: An analysis of 123 episodes, with particular emphasis on the effect of antibiotic therapy. Int J Infect Dis 2: 211-215, 1998.

16. Kim YJ, Jun YH, Yang RK, Park KG, Park YJ, Kang JY and Kim SI: Risk factors for mortality in patients with Pseudomonas aeruginosa bacteremia; retrospective study of impact of combination antimicrobial therapy. BMC Infect Dis 14: 161, 2014.

17. Samonis G, Vardakas KZ, Kofteridis DP, Dimopoulou D, Andrianaki AM, Chatzinikolaou I, Katsanevaki E, Maraki S and Falagas ME: Characteristics, risk factors and outcomes of adult cancer patients with extensively drug-resistant Pseudomonas aeruginosa infections. Infection 42. 721-728, 2014.

18. Peña C, Suarez C, Ocampo-Sosa A, Murillas J, Almirante B, Pomar V, Aguilar M, Granados A, Calbo E, Rodríguez-Baño J, et al: Effect of adequate single-drug vs combination antimicrobial therapy on mortality in Pseudomonas aeruginosa bloodstream infections: A post Hoc analysis of a prospective cohort. Clin Infect Dis 57: 208-216, 2013.

19. Hilf M, Yu VL, Sharp J, Zuravleff JJ, Korvick JA and Muder RR: Antibiotic therapy for Pseudomonas aeruginosa bacteremia: Outcome correlations in a prospective study of 200 patients. Am J Med 87: 540-546, 1989.

20. Leibovici L, Paul M, Poznanski O, Drucker M, Samra Z, Konigsberger $\mathrm{H}$ and Pitlik SD: Monotherapy versus beta-lactam-aminoglycoside combination treatment for gram-negative bacteremia: A prospective, observational study. Antimicrob Agents Chemother 41: 1127-1133, 1997.

21. Kuikka A and Valtonen VV: Factors associated with improved outcome of Pseudomonas aeruginosa bacteremia in a Finnish university hospital. Eur J Clin Microbiol Infect Dis 17: 701-708, 1998.

22. Mendelson MH, Gurtman A, Szabo S, Neibart E, Meyers BR, Policar M, Cheung TW, Lillienfeld D, Hammer G, Reddy S, et al: Pseudomonas aeruginosa bacteremia in patients with AIDS. Clin Infect Dis 18: 886-895, 1994.

23. Park SY, Park HJ, Song MM, Park KH, Chong YP, Kim MN, Kim SH, Lee SO, Kim YS, Woo JH and Choi SH: Impact of adequate empirical combination therapy on mortality from bacteremic Pseudomonas aeruginosa pneumonia. BMC Infect Dis 12: 308, 2012.

24. Yoon YK, Kim HA, Ryu SY, Lee EJ, Lee MS, Kim J, Park SY, Yang KS and Kim SW; Antibiotic Stewardship StudyGroup: Tree-structured survival analysis of patients with Pseudomonas aeruginosa bacteremia: A multicenter observational cohort study. Diagn Microbiol Infect Dis 87: 180-187, 2017.
25. Tan SH, Teng CB, Ng TM and Lye DC: Antibiotic therapy and clinical outcomes of Pseudomonas aeruginosa (PA) bacteraemia. Ann Acad Med Singapore 43: 526-534, 2014.

26. Stang A: Critical evaluation of the Newcastle-Ottawa scale for the assessment of the quality of nonrandomized studies in meta-analyses. Eur J Epidemiol 25: 603-605, 2010.

27. Yang WS, Va P, Wong MY, Zhang HL and Xiang YB: Soy intake is associated with lower lung cancer risk: Results from a meta-analysis of epidemiologic studies. Am J Clin Nutr 94: 1575-1583, 2011.

28. Yang Y, Zhang D, Feng N, Chen G, Liu J, Chen G and Zhu Y: Increased intake of vegetables, but not fruit, reduces risk for hepatocellular carcinoma: A meta-analysis. Gastroenterology 147: 1031-1042, 2014.

29. Zhang Y, Zheng QJ, Wang S, Zeng SX, Zhang YP, Bai XJ and Hou TY: Diabetes mellitus is associated with increased risk of surgical site infections: A meta-analysis of prospective cohort studies. Am J Infect Control 43: 810-815, 2015.

30. Gu WJ, Wang F, Tang L and Liu JC: Single-dose etomidate does not increase mortality in patients with sepsis: A systematic review and meta-analysis of randomized controlled trials and observational studies. Chest 147: 335-346, 2015.

31. Ownby RL, Crocco E, Acevedo A, John V and Loewenstein D: Depression and risk for Alzheimer disease: Systematic review, meta-analysis, and metaregression analysis. Arch Gen Psychiatry 63: 530-538, 2006

32. Lo CK, Mertz D and Loeb M: Newcastle-Ottawa Scale: Comparing reviewers' to authors' assessments. BMC Med Res Methodol 14: 45, 2014.

33. Larsson SC, Orsini N and Wolk A: Vitamin B6 and risk of colorectal cancer: A meta-analysis of prospective studies. JAMA 303: 1077-1083, 2010.

34. Higgins JP, Thompson SG, Deeks JJ and Altman DG: Measuring inconsistency in meta-analyses. BMJ 327: 557-560, 2003.

35. Higgins JP and Green S (eds): Cochrane Handbook for Systematic Reviews of Interventions Version 5.1.0. The Cochrane Collaboration, 2011. http://handbook.cochrane.org. Updated March 2011.

36. DerSimonian R and Laird N: Meta-analysis in clinical trials. Control Clin Trials 7: 177-188, 1986

37. Sterne JA and Egger M: Funnel plots for detecting bias in meta-analysis: Guidelines on choice of axis. J Clin Epidemiol 54: 1046-1055, 2001

38. Traugott KA, Echevarria K, Maxwell P, Green K and Lewis JS II: Monotherapy or combination therapy? The Pseudomonas aeruginosa conundrum. Pharmacotherapy 31: 598-608, 2011.

39. Chatzinikolaou I, Abi-Said D, Bodey GP, Rolston KV, Tarrand JJ and Samonis G: Recent experience with Pseudomonas aeruginosa bacteremia in patients with cancer: Retrospective analysis of 245 episodes. Arch Intern Med 160: 501-509, 2000.

40. Safdar N, Handelsman J and Maki DG: Does combination antimicrobial therapy reduce mortality in Gram-negative bacteraemia? A meta-analysis. Lancet Infect Dis 4: 519-527, 2004.

41. Zhang Y, Chen XL, Huang AW, Liu SL, Liu WJ, Zhang N and $\mathrm{Lu}$ XZ: Mortality attributable to carbapenem-resistant Pseudomonas aeruginosa bacteremia: A meta-analysis of cohort studies. Emerg Microbes Infect 5: e27, 2016.

42. Vardakas KZ, Tansarli GS, Bliziotis IA and Falagas ME: $\beta$-Lactam plus aminoglycoside or fluoroquinolone combination versus $\beta$-lactam monotherapy for Pseudomonas aeruginosa infections: A meta-analysis. Int J Antimicrob Agents 41: 301-310, 2013.

43. Hu Y, Li L, Li W, Xu H, He P, Yan X and Dai H: Combination antibiotic therapy versus monotherapy for Pseudomonas aeruginosa bacteraemia: A meta-analysis of retrospective and prospective studies. Int J Antimicrob Agents 42: 492-496, 2013.

This work is licensed under a Creative Commons Attribution-NonCommercial-NoDerivatives 4.0 International (CC BY-NC-ND 4.0) License. 